\title{
Research Note: Total Free Sulphydryls of Several White and Red Wines
}

\author{
N. Kontogeorgos, I.G. Roussis* \\ Laboratory of Food Chemistry, Department of Chemistry, University of Ioannina, 45110 Ioannina, Greece \\ Submitted for publication: September 2013 \\ Accepted for publication: February 2014
}

Key words: Wine, total free sulphydryls

\begin{abstract}
Total free sulphydryl groups were assessed in several white and red wines. Ellman's method was adapted to wine samples for the determination of total-SH groups. Total-SH groups of white wines, as glutathione, were in the range of 315 to 734 and of red wines in the range of 163 to $467 \mathrm{mg} / \mathrm{L}$. In most cases, white wines exhibited higher values than red wines. The high total sulphydryls of white and red wines indicate their potential contribution to wine antioxidant capacity.
\end{abstract}

\section{INTRODUCTION}

Wines are rich pools of natural antioxidants. Phenolics are their major antioxidants, while amino acids and peptides containing - $\mathrm{SH}$ are also present. Wines contain several mg of the tripeptide glutathione, and also some amounts of other thiols such as cysteine and $\mathrm{N}$-acetyl-cysteine. Glutathione retards must oxidation and possibly plays a role in wine browning. Moreover, glutathione and also N-acetyl-cysteine protect several wine aroma volatiles (Singleton et al., 1985; Cheynier et al., 1986; Vaimakis \& Roussis, 1996; Park et al., 2000; Papadopoulou \& Roussis, 2001; Dubourdieu \& Lavigne-Cruege, 2004; Roussis et al., 2007; Papadopoulou \& Roussis, 2008; Roussis \& Sergianitis, 2008; El Horsy et al., 2009; Roussis et al., 2009; Kritzinger et al., 2013). Some thiols play significant physiological roles in vivo as nucleophiles and scavengers of free radicals (Friedman, 1994, 1996). However, there are no reports about the potential impact of wine glutathione and other thiols on human health.

Amino acids and peptides containing free $-\mathrm{SH}$ in wines are determined by HPLC methods and also by capillary electrophoresis (Cheynier et al., 1989; Lavigne et al., 2007; Du Toit et al., 2007). Moreover, a spectrophotometric procedure has been reported for the determination of total sulphydryls in red wines (Cimino et al., 2007).

The aim of the present work was to determine the total free sulphydryl groups of white and red wines. To aid in this effort, Ellman's method for the assessment of sulphydryls was adapted.

\section{MATERIALS AND METHODS}

DTNB (5,5'-dithio-bis (2-nitrobenzoic acid) reagent, glutathione and absolute ethanol were purchased from Sigma-Aldrich, while TPTZ, 2,4,6-Tri-2-pyridyl-1,3,5triazine and $(2 \mathrm{R}, 3 \mathrm{R})-(+)$-tartaric acid of $99.0 \%$ purity were purchased from Merck. A Consort C831 pH-meter, an analytical balance Kern 770 and a Jenway 6505 UV/Vis spectrophotometer with glass or quartz cells of $1 \mathrm{~cm}$ were used.

Twenty-two dry wines from Greek vineyards were examined. Moschofilero, Assyrtiko, Moschato Alexandrias, Robola, Debina, Roditis, Agiorgitiko and Xinomavro wines were classed as "Appellation of Origin", while Vilana, Athiri, Savatiano, Malagousia, Trebbiano, Chardonnay, Traminer, Riesling, Sauvignon blanc, Cabernet Sauvignon, KotsifaliMandilaria blend, Limnio, Merlot and Syrah were regional wines. Most of the white wines were one year old, while Traminer and Riesling were two years old. Most red wines were two years old, while Xinomavro was three years old.

Total free sulphydryl groups $(-\mathrm{SH})$ were determined using Ellman's reagent (Ellman, 1959; Bulaj et al., 1998). In brief, $2.4 \mathrm{~mL}$ of phosphate buffer $\left(\mathrm{K}_{2} \mathrm{HPO}_{4} / \mathrm{KH}_{2} \mathrm{PO}_{4}, 200\right.$ $\mathrm{mM}, \mathrm{pH}$ 7.4) were mixed with $0.6 \mathrm{~mL}$ of wine sample (wine diluted 1:10 with model wine). Then, $0.3 \mathrm{~mL}$ of DTNB (5,5'-dithio-bis (2-nitrobenzoic acid) solution (1 $\mathrm{mM}$ in the same phosphate buffer) were added and the mixture was kept at $20^{\circ} \mathrm{C}$ for $1 \mathrm{~h}$. For each sample, the absorbance at $412 \mathrm{~nm}$ was measured against a blank containing buffer instead of the DTNB solution. Moreover, the absorbance of a mixture consisting of $2.4 \mathrm{~mL}$ phosphate buffer, $0.6 \mathrm{~mL}$ model wine and $0.3 \mathrm{~mL}$ of the DTNB solution was subtracted from the sample absorbance. The spectrophotometer was set at zero using distilled $\mathrm{H}_{2} \mathrm{O}$. Results were expressed as glutathione equivalent. For this, glutathione solutions (0, 10, 20, 40, 80, $120 \mathrm{mg} / \mathrm{L})$ in model wine were used instead of wine samples $\left(\mathrm{C}=148 \times\right.$ Absorbance, $\left.\mathrm{R}^{2}=0.9996\right)$.

For the standardisation of conditions used in $-\mathrm{SH}$ determination, preliminary experiments were done using glutathione solutions in model wine and also wine. Using glutathione solutions, we used increasing concentrations 
of phosphate buffer with different $\mathrm{pH}$ values. Measured absorbances increased by increasing the concentration and/or $\mathrm{pH}$ values of the buffer used. Maximum absorbances were taken using $200 \mathrm{mM}$ and $\mathrm{pH}$ 7.4. Similar results were also obtained to those using $1 \mathrm{M}$ phosphate buffer, $\mathrm{pH} 8.0$ $\left(\mathrm{C}=143 \mathrm{x}\right.$ absorbance with an $\left.\mathrm{R}^{2}=0.9986\right)$. Moreover, we used 20 or $30^{\circ} \mathrm{C}$ for the reaction temperature and similar results were obtained. Similar results were also achieved using reaction times of one or two hours. We therefore chose

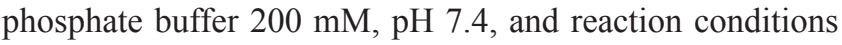
of one hour at $20^{\circ} \mathrm{C}$. Finally, we applied the chosen conditions using different dilutions of a white (Roditis) and a red (Xinomavro) wine. For Roditis the equation was Concentration $=0.31 \times$ Absorbance with $\mathrm{R}^{2}=0.9978$, and for Xinomavro it was Concentration (fraction of wine in the unit of sample used) $=0.47 \times$ Absorbance with $\mathrm{R}^{2}=$ 0.9982 . Wine concentration was defined as $1 /$ dilution fold. After these preliminary experiments, we used the chosen conditions for the determination of total sulphydryls in 15 white and 7 red wines.

The model wine used consisted of $12 \%$ ethanol and 5 $\mathrm{g} / \mathrm{L}$ tartaric acid in water, with the $\mathrm{pH}$ adjusted to $3.5 \mathrm{using}$ $1 \mathrm{~N} \mathrm{NaOH}$.

All analyses were done in triplicate and the results reported are the means along with the standard deviations.

\section{RESULTS AND DISCUSSION}

We standardised a procedure for the determination of total free sulphydryls in wines using Ellman's reagent. Preliminary work had shown that the concentration and $\mathrm{pH}$ of the phosphate buffer used play a significant role, and that the chosen characteristics of the buffer (200 mM, pH 7.4) give maximum results. In Fig. 1, total free sulphydryls of different dilutions of a white and a red wine are presented. In both cases a linear equation was taken by plotting $-\mathrm{SH}$ values and wine dilution, indicating the suitability of the procedure.
Table 1 shows the total free sulphydryl groups of several white and red wines, expressed as glutathione equivalent in $\mathrm{mg} / \mathrm{L}$. In most cases, white wines exhibited higher total free sulphydryls than red wines. The range of 14 of the 15 white wines was 425 to $734 \mathrm{mg} / \mathrm{L}$ and of six of the seven red wines was 163 to $333 \mathrm{mg} / \mathrm{L}$. One white wine (Riesling) exhibited a value $(315 \mathrm{mg} / \mathrm{L})$ in the range of red wines, and one red wine (Kotsifali-Mandilaria blend) had a value $(467 \mathrm{mg} / \mathrm{L})$ in the range of white wines. In another work, total free -SH groups in red wines were determined and the values reported were much lower than the values in the present work (Cimino et al., 2007). However, this difference is due rather to the methodologies applied. It is possible that only part of total free - $\mathrm{SH}$ groups was determined in the previous work due to the low concentration of the phosphate buffer used.

The method used determines the total free sulphydryls, i.e. the sum of the total free sulphydryl groups of amino acids-small peptides and those of polypeptides-proteins. So, the higher values of white wines can be attributed to the removal of polypeptides-proteins from the red wines, after their reaction with tannins. Among wine thiol amino acidsmall peptides, it is known that glutathione plays a significant role in must oxidation and wine aroma protection, and it exists in higher concentrations than the others (Vaimakis \& Roussis, 1996; Papadopoulou \& Roussis, 2001; Dubourdieu \& Lavigne-Cruege, 2004; Du Toit et al., 2007; Lavigne et al., 2007; Roussis et al., 2007; Papadopoulou \& Roussis, 2008; Roussis \& Sergianitis, 2008; Roussis et al., 2009; Kritzinger et al., 2013).

On the other hand, there are no reports on the potential antioxidant action of polypeptides-proteins containing free $-\mathrm{SH}$. It has been shown that the antioxidant and aroma protection activities of some thiols in foods are due to their free sulphydryl group (Roussis et al., 2009). It therefore could be expected that free sulphydryls of polypeptidesproteins contribute to wine antioxidant capacity.

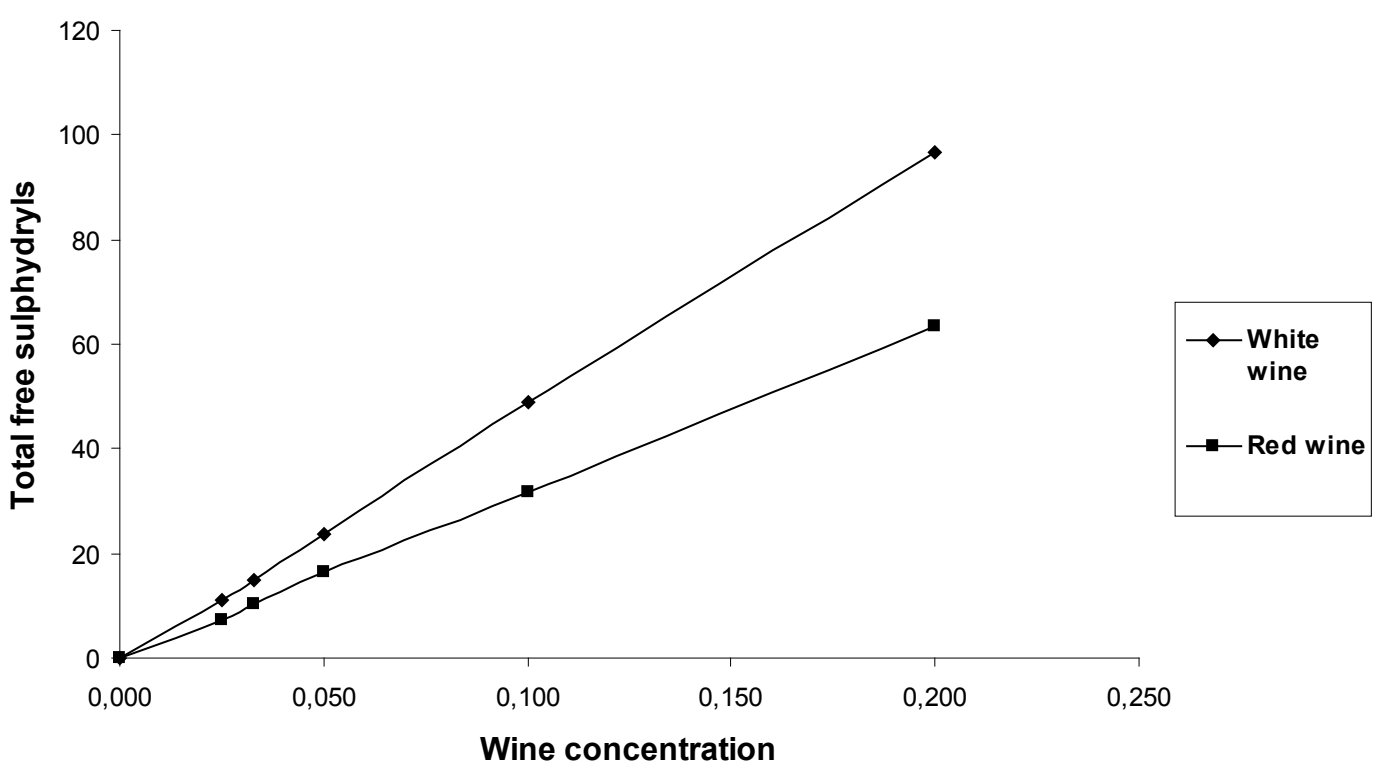

FIGURE 1

Total free sulphydryls of different concentrations (dilutions) of a white (Roditis) and a red (Xinomavro) wine. Total sulphydryl groups were expressed as glutathione equivalent in $\mathrm{mg} / \mathrm{L}$. Wine concentration was defined as 1/dilution fold. 
TABLE 1

Total sulphydryl groups of several white and red wines.

\begin{tabular}{|c|c|c|c|}
\hline White wines & Total-SH & Red wines & Total -SH \\
\hline Moschofilero & $425 \pm 4$ & Agiorgitiko & $239 \pm 2$ \\
\hline Assyrtiko & $472 \pm 4$ & Cabernet Sauvignon & $163 \pm 3$ \\
\hline Vilana & $435 \pm 3$ & Kotsifali-Mandilaria blend & $467 \pm 1$ \\
\hline Muscat of Alexandria & $427 \pm 1$ & Limnio & $352 \pm 3$ \\
\hline Athiri & $734 \pm 4$ & Xinomavro & $333 \pm 7$ \\
\hline Robola & $573 \pm 3$ & Merlot & $185 \pm 4$ \\
\hline Debina & $603 \pm 2$ & Syrah & $174 \pm 1$ \\
\hline Savatiano & $502 \pm 4$ & Mean/range & $273 / 163-467$ \\
\hline Malagousia & $431 \pm 2$ & & \\
\hline Trebbiano & $622 \pm 4$ & & \\
\hline Roditis & $514 \pm 2$ & & \\
\hline Chardonnay & $645 \pm 5$ & & \\
\hline Traminer & $567 \pm 4$ & & \\
\hline Riesling & $315 \pm 2$ & & \\
\hline Sauvignon blanc & $436 \pm 5$ & & \\
\hline Mean/range & $513 / 315-734$ & & \\
\hline
\end{tabular}

Total sulphydryl groups (-SH) were expressed as glutathione equivalent in mg/L.

Values are the means of analysis in triplicate along with standard deviation.

\section{CONCLUSIONS}

The present results show that wines exhibit high concentrations of total free sulphydryls, as determined by an appropriate adaptation of Ellman's method.

\section{LITERATURE CITED}

Bulaj, G., Kortemme, T. \& Goldenberg, D.P., 1998. Ionization-reactivity relationships for cysteine thiols in polypeptides. Biochem. 37, 8965-8972.

Cheynier, V., Souquet, J.M. \& Moutounet, M., 1989. Glutathione content and glutathione to hydroxycinnamic acid ratio in Vitis vinifera grapes and musts. Am. J. Enol. Vitic. 40, 320-324.

Cheynier, V., Trousdale, E., Singleton, V.L., Salgues, M. \& Wylde, R., 1986. Characterization of 2-s-glutathionyl caftaric acid and its hydrolysis in relation to grape wines. J. Agric. Food Chem. 34, 217-221.

Cimino, F., Sulfaro, V., Trombetta, D., Saija, A. \& Tomaino, A., 2007. Radical-scavenging capacity of several Italian red wines. Food Chem. 103, 75-81.

Dubourdieu, D. \& Lavigne-Cruege, V., 2004. The role of glutathione on the aromatic evolution of dry white wine. Wine Internet Techn. J. 2, 1-9.

Du Toit, W.J., Lisjak, K., Stander, M. \& Prevoo, D., 2007. Using LC-MSMS to assess glutathione levels in South African white grape juices and wines made with different levels of oxygen. J. Agric. Food Chem. 55, 2765-2769.

El Hosry, L., Auezova, L., Sakr, A. \& Hajj-Moussa, E., 2009. Browning susceptibility of white wine and antioxidant effect of glutathione. Int. J. Food Sci. Technol. 44, 2459-2463.

Ellman, G.L., 1959. Tissue sulfhydryl groups. Arch. Biochem. Biophys. 82, 70-77.

Friedman, M., 1994. Improvement in the safety of foods by SH-containing amino acids and peptides. A review. J. Agric. Food Chem. 42, 3-20.

Friedman, M., 1996. Food browning and its prevention - an overview. J. Agric. Food Chem. 44, 631-653.
Kritzinger, E.C., Bauer, F.F. \& Du Toit, W.J., 2013. Role of glutathione in wine: A review. J. Agric. Food Chem. 61, 269-277.

Lavigne, V., Pons, A. \& Dubourdieu, D., 2007. Assay of glutathione in must and wine using capillary electrophoresis and laser-induced fluorescence detection: changes in concentration in dry white wines during alcoholic fermentation and ageing. J. Chrom. A 1139, 130-135.

Papadopoulou, D. \& Roussis, I.G., 2001. Inhibition of the decline of linalool and $\alpha$-terpineol in Muscat wines by glutathione and $\mathrm{N}$-acetyl-cysteine. Ital J. Food Sci. 13, 413-419.

Papadopoulou, D. \& Roussis, I.G., 2008. Inhibition of the decrease of volatile esters and terpenes during storage of a white wine and a model wine medium by glutathione and N-acetyl-cysteine. Int. J. Food Sci. Technol. 43, 1053-1057.

Park, S.K., Boulton, R.B. \& Noble, A.C., 2000. Automated HPLC analysis of glutathione and thiol-containing compounds in grape juice and wine using pre-column derivatization with fluorescence detection. Food Chem $68,475-480$.

Roussis, I.G. \& Sergianitis, S., 2008. Protection of some aroma volatiles in a model wine medium by sulphur dioxide and mixtures of glutathione with caffeic acid or gallic acid. Flav. Fragr. J. 23, 35-39.

Roussis, I.G., Lambropoulos, I. \& Tzimas, P., 2007. Protection of volatiles of a wine with low sulfur dioxide by caffeic acid or glutathione. Am. J. Enol. Vitic. 58, 274-278.

Roussis, I.G., Papadopoulou, D. \& Sakarellos-Daitsiotis, M., 2009 Protective effect of thiols on wine aroma volatiles. Open Food Sci. J. 3, 98.

Singleton, V.L., Salgues, M., Zaya, J. \& Trousdale, E., 1985. Caftaric acid disappearance and conversion to products of enzymic oxidation in grape must and wine. Am. J. Enol. Vitic. 36, 50-56.

Vaimakis, V. \& Roussis, I.G., 2005. Must oxygenation together with glutathione addition in the oxidation of white wine. Food Chem. 57, 419422. 